\title{
Hemispheric surgery for refractory epilepsy: a systematic review and meta-analysis with emphasis on seizure predictors and outcomes
}

\author{
Wen-Han Hu, MD, PhD, ${ }^{1}$ Chao Zhang, MD, ${ }^{2}$ Kai Zhang, MD, PhD, ${ }^{2}$ Xiao-Qiu Shao, MD, PhD, ${ }^{3}$ and \\ Jian-Guo Zhang, MD, PhD ${ }^{1,2}$
}

\begin{abstract}
${ }^{1}$ Beijing Neurosurgical Institute and Departments of 2 Neurosurgery and ${ }^{3}$ Neurology, Beijing Tiantan Hospital, Capital Medical University, Beijing, China
\end{abstract}

\begin{abstract}
OBJECTIVE Conflicting conclusions have been reported regarding several factors that may predict seizure outcomes after hemispheric surgery for refractory epilepsy. The goal of this study was to identify the possible predictors of seizure outcome by pooling the rates of postoperative seizure freedom found in the published literature.
\end{abstract}

METHODS A comprehensive literature search of PubMed, Embase, and the Cochrane Library identified English-language articles published since 1970 that describe seizure outcomes in patients who underwent hemispheric surgery for refractory epilepsy. Two reviewers independently assessed article eligibility and extracted the data. The authors pooled rates of seizure freedom from papers included in the study. Eight potential prognostic variables were identified and dichotomized for analyses. The authors also compared continuous variables within seizure-free and seizure-recurrent groups. Random- or fixed-effects models were used in the analyses depending on the presence or absence of heterogeneity.

RESULTS The pooled seizure-free rate among the 1528 patients (from 56 studies) who underwent hemispheric surgery was $73 \%$. Patients with an epilepsy etiology of developmental disorders, generalized seizures, nonlateralization on electroencephalography, and contralateral MRI abnormalities had reduced odds of being seizure-free after surgery.

CONCLUSIONS Hemispheric surgery is an effective therapeutic modality for medically intractable epilepsy. This metaanalysis provides useful evidence-based information for the selection of candidates for hemispheric surgery, presurgical counseling, and explanation of seizure outcomes.

http://thejns.org/doi/abs/10.3171/2015.4.JNS14438

KEY WORDS hemispheric surgery; hemispherectomy; hemispherotomy; hemidecortication; meta-analysis; epilepsy

$\mathrm{H}$ EMISPHERIC surgery is a well-accepted treatment modality for medically refractory epilepsy induced by hemispheric abnormalities, such as Rasmussen encephalitis, cortical dysplasia, Sturge-Weber syndrome, hemimegalencephaly, or encephalomalacia. Since the anatomical hemispherectomy $(\mathrm{AH})$ procedure was performed by Dandy for glioma in 1928 and introduced by McKenzie for epilepsy in 1938, several hemispheric surgical techniques have been developed, including functional hemispherectomy (FH) and hemispherotomy. ${ }^{16,50} \mathrm{The} \mathrm{AH}$ technique was classically applied in the 1950s and the 1960s. The popularity of the AH technique declined in the late 1960s because of its delayed complications such as obstructive hydrocephalus, superficial hemosiderosis, and intracranial hematomata. ${ }^{56}$ The advent of $\mathrm{FH}$, which was first described by Rasmussen in 1983, ${ }^{56}$ has increased the use of hemispheric surgery for drug-resistant epilepsy. However, in 1995, both Schramm et al. ${ }^{61}$ and Villemure and Mascott ${ }^{77}$ simultaneously introduced a modified version of the FH technique, termed "hemispherotomy," that has replaced traditional FH in many epilepsy centers.

In published studies, seizure outcomes in patients who underwent hemispheric surgery for refractory epilepsy have varied, with rates of seizure freedom ranging from

ABBREVIATIONS AH = anatomical hemispherectomy; EEG = electroencephalography; FCD = focal cortical dysplasia; FH = functional hemispherectomy; OR = odds ratio; $\mathrm{PET}=$ positron emission tomography; $\mathrm{WMD}=$ weighted mean difference.

SUBMITTED February 25, 2014. ACCEPTED April 7, 2015.

INCLUDE WHEN CITING Published online October 23, 2015; DOI: 10.3171/2015.4.JNS14438. 
$33 \%$ to $92 \% .^{22,71}$ Given the substantial variability in seizure outcomes after surgery, many studies have attempted to identify prognostic variables that may predict postoperative seizure outcomes. Most of these studies focused on predictors such as the etiology of epilepsy, ${ }^{51}$ contralateral $\mathrm{MRI}^{4,51}$ and electroencephalography (EEG) findings, ${ }^{51}$ or surgical techniques. ${ }^{63}$ However, conflicting results have been reported from these studies. Moreover, little attention has been paid to other possible factors that may correlate with seizure freedom, including seizure semiology or epilepsy duration. In the present study, we performed a systematic review and meta-analysis of published studies involving hemispheric surgery in patients with refractory epilepsy induced by hemispheric diseases. The goals of our study were 1) to calculate the postoperative seizurefree rate pooled from published studies and 2) to identify possible prognostic indicators for seizure outcomes after hemispheric surgery.

\section{Methods \\ Search Strategy}

A comprehensive literature search of PubMed, Embase, and the Cochrane Library was performed by 2 authors using the following terms alone or in combination: hemispherectomy, hemispheric surgery, hemispherotomy, hemidecortication, hemicorticectomy, epilepsy, and seizure. The literature search strategy used with PubMed was as follows: (hemispherectomy[TIAB] OR hemispheric surgery[TIAB] OR hemispherotomy[TIAB] OR hemidecortication[TIAB] OR hemicorticectomy[TIAB]) AND (epilepsy[TIAB] OR seizure[TIAB]); the limits included publication years 1970-2013 and English-language articles. The bibliographies of original articles, reviews, and book chapters were also searched to find additional relevant studies. Searches were restricted to fulllength English-language articles published from 1970 to 2013.

\section{Study Selection, Data Extraction, and Quality Assessment}

Two authors independently reviewed the abstract or full text of each retrieved article and applied the following study inclusion criteria: 1) papers contained postoperative seizure outcomes collected from at least 5 patients undergoing hemispheric surgery for refractory epilepsy, 2) papers contained seizure outcomes reported after a mean or median follow-up period $\geq 1$ year, and 3) papers contained seizure outcomes measured using Engel's classification scale or other comparable schemes. Studies with possible overlapping patient populations from the same medical center were excluded, and only the most recent or complete study was included in our analysis. When possible, we divided data into dichotomous groups according to the following variables: sex (male vs female), etiology of epilepsy (developmental vs nondevelopmental), seizure semiology (partial only vs generalized), interictal EEG lateralization (present vs absent), ictal EEG lateralization (present vs absent), contralateral MRI abnormalities (present vs absent), surgery type (techniques based on complete cortical removal vs disconnective techniques, as proposed by De Almeida et al..), ${ }^{19}$ and side of resection (right vs left).
In the correlation analysis between etiology and seizure outcome, we classified cortical dysplasia, hemimegalencephaly, or tuberous sclerosis complex as developmental etiologies, and we classified other diseases such as encephalomalacia, Rasmussen encephalitis, Sturge-Weber syndrome, or cerebral tumor as nondevelopmental etiologies. In the analyses of dichotomous variables, data for individual variables in each study were excluded if dichotomous groups could not be formed. The primary outcome was seizure freedom as defined by the authors' description from the last reported follow-up in each study. We also extracted data from continuous variables, including patient age at onset, age at surgery, and epilepsy duration. Two authors independently extracted all the data, and discrepancies were resolved through discussion. Because all studies included in the analysis were case-control studies, the methodological quality of individual studies, which was associated with the risk of bias, was evaluated using the modified Newcastle-Ottawa Scale. This scale uses a star-rating system to assess 3 categories, including patient selection, comparability of the study groups, and exposure assessment.

\section{Analysis}

The unit of analysis was each published paper. The rates of seizure freedom were pooled from all papers included in the study. Seizure outcomes were compared within dichotomous groups to determine if a significant correlation existed between the variable and seizure outcomes. We also compared continuous variables between seizure-free (Engel Class I) and seizure-recurrent (Engel Class II-IV) groups. The odds ratio (OR) and weighted mean difference (WMD), along with their $95 \%$ confidence intervals (CIs), were used in the analysis of dichotomous and continuous variables, respectively. The heterogeneity between studies was assessed by means of Q statistics, and $\mathrm{I}^{2} \geq 50 \%$ was considered substantial heterogeneity. Publication bias was assessed graphically by the use of funnel plots. The analysis of pooled rates of seizure freedom was performed with R version 3.0.2 (R Foundation for Statistical Computing), and the analyses of associations between the variables and seizure outcomes were performed with Review Manager version 5.2 (Revman; the Cochrane Collaboration). Random- or fixed-effects models were used in all analyses, depending on the presence or absence of heterogeneity. When variables were identified as prognostic factors, we performed sensitivity analysis to evaluate the stability of the results by changing the effects models. Statistical significance was set at $\mathrm{p} \leq 0.05$.

\section{Results \\ Evidence Base}

The initial literature search yielded 1282 records, of which 807 remained after duplication screening. In the title and abstract review, 242 potentially eligible papers were identified. After a full-text review, a total of 56 articles (representing 1528 patients) fulfilled the predefined inclusion criteria and were included in the study (Fig. 1). ${ }^{1,2,4-6,8,12,13,15,17,18,20-24,30-32,34-40,42,44-49,51-55,60,62-64,65,67-76,79-81}$ As shown in Table 1, all 56 articles are case-control stud- 


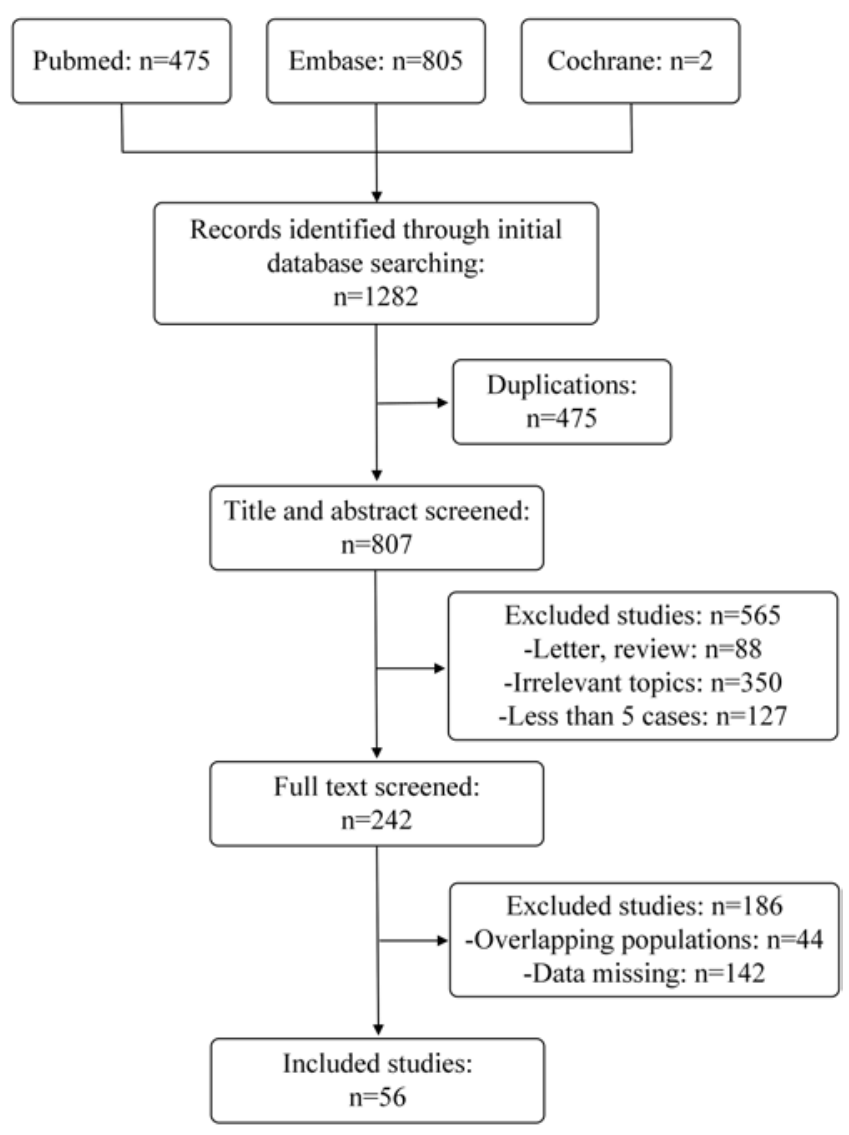

FIG. 1. Summary of the literature search strategy.

ies that scored 6 or 7 stars on the modified NewcastleOttawa Scale.

\section{Pooled Seizure Freedom Rate}

The pooled rate of postoperative seizure freedom from the 56 papers was $73 \%$ (95\% CI 71\%-75\%) with an $\mathrm{I}^{2}$ value of $30.8 \%$, which indicated that there was no significant heterogeneity. A funnel plot of the analysis showed that all papers were located within the funnel except for 4 , and the distribution of papers included in the study was roughly symmetrical, suggesting a mild publication bias.

\section{Factors Predicting Seizure Outcome}

Table 2 shows the results of the 8 meta-analyses performed to assess correlations between dichotomous variables and seizure outcomes. Male and female patients had similar odds of being seizure-free after hemispheric surgery (OR 1.15, 95\% CI 0.79-1.67, p = 0.46). Patients with epilepsy induced by developmental disorders had lower odds of achieving postoperative seizure freedom (OR 0.61, 95\% CI 0.46-0.82, p = 0.001; Fig. 2A) than those with epilepsy induced by nondevelopmental diseases. With respect to seizure semiology, the absence of generalized seizures (partial only) was associated with favorable seizure outcomes (OR 1.84, 95\% CI 1.18-2.89, p = 0.008; Fig. 2B). Lateralized findings on interictal or ictal EEG also appeared to correlate with improved seizure outcomes (interictal: OR 1.66, 95\% CI 1.03-2.67, p = 0.04, Fig. 2C; ictal: OR
1.88, 95\% CI 1.15-3.07, $\mathrm{p}=0.01$, Fig. 3A). The presence of contralateral MRI abnormalities reduced the odds of seizure control after surgery (OR $0.46,95 \%$ CI $0.27-0.77$, $\mathrm{p}=0.004$; Fig. 3B). Surgical technique did not affect postoperative seizure outcomes (OR 1.51, 95\% CI 0.96-2.36, $\mathrm{p}=0.07$ ), nor did the side of resection (OR 1.17, 95\% CI $0.79-1.73, p=0.43$ ). Q statistics and funnel plots showed there was no significant study heterogeneity or publication bias in each analysis. In the sensitivity analyses for seizure outcome predictors, the random-effects model was used, and the result of each study did not alter.

Table 3 shows comparison data between seizure-free and seizure-recurrent groups with respect to the abovementioned 3 continuous variables. Patients with poor seizure control appeared to have had a history of earlier seizure onset (WMD $0.43,95 \%$ CI $0.07-0.79, \mathrm{p}=0.02$ ) and younger age at surgery (WMD 1.15, 95\% CI 0.07-2.23, $\mathrm{p}=0.04$ ), while substantial heterogeneities across studies in the 2 analyses were noted $\left(\mathrm{I}^{2}=66 \%\right.$ and $63 \%$, respectively). The patients in seizure-free and seizure recurrent groups had similar epilepsy durations (WMD 0.55, 95\% CI -0.32 to $1.41, p=0.22$ ), and significant study heterogeneity was also observed $\left(\mathrm{I}^{2}=50 \%\right)$.

\section{Discussion}

In the present study, we performed a systematic review and meta-analysis identifying the rate and predictors of postoperative seizure freedom in 1528 patients (across 56 studies) who underwent hemispheric surgery for medically refractory epilepsy. We found the pooled rate of seizure freedom to be $73 \%$ with a $95 \%$ CI of $71 \%$ to $75 \%$, and the factors associated with favorable seizure outcomes included an epilepsy etiology of nondevelopmental diseases, absence of generalized seizures, lateralized findings on interictal or ictal EEG, and the absence of contralateral MRI abnormalities.

Hemispheric surgical techniques, including $\mathrm{AH}, \mathrm{FH}$, hemispherotomy, and their associated modifications, have proven to be effective in refractory epilepsy control. However, according to previous studies and our own analysis, approximately $30 \%$ of patients still suffer from persistent seizures after surgery. ${ }^{12,20,30} \mathrm{~A}$ better understanding of seizure outcome predictors is crucial for neurosurgeons to identify surgical candidates and counsel patients and their families on the possibility of seizure recurrence after surgery. Previous studies have assessed epilepsy etiology as a prognostic indicator of seizure outcome, and conflicting conclusions have been reported ${ }^{40,51,63}$ The results of the present study are consistent with the opinion of Kossoff et al. ${ }^{40}$ who reported that developmental disorders negatively influence seizure outcomes. There is a large spectrum of malformations in cortical development; cortical dysplasia was the most common developmental etiology in our analysis. Although the majority of cortical dysplasia is located on 1 hemisphere, bilateral cortical dysplasia was occasionally observed in some patients. ${ }^{27,28,41,66,82}$ Moreover, not all cortical dysplasia could be identified by routine MRI during the preoperative evaluation. A study by Lerner et al. showed that, on average, $37 \%$ and $15 \%$ of lesions from focal cortical dysplasia (FCD) Type I and 
TABLE 1. Studies included in the analyses

\begin{tabular}{|c|c|c|c|c|c|c|}
\hline Authors \& Year & Study Origin & $\begin{array}{c}\text { Patient Age at } \\
\text { Op }(y r s)^{*}\end{array}$ & $\begin{array}{c}\text { Duration of } \\
\text { Epilepsy }(\mathrm{yrs})^{*}\end{array}$ & Follow-Up (yrs)* & $\begin{array}{c}\text { No. \& Rate of } \\
\text { Seizure Freedom }\end{array}$ & $\begin{array}{l}\text { Total No. of } \\
\text { Patients }\end{array}$ \\
\hline Basheer et al., 2007 & Canada & 3.47 & NA & 6.6 & $19(79.17 \%)$ & 24 \\
\hline Beardsworth \& Adams, 1988 & UK & 11.5 & 4.37 & 3.88 & $7(70 \%)$ & 10 \\
\hline Boshuisen et al., 2010 & Netherlands & 4.1 & 2.9 & 6.9 & $33(76.74 \%)$ & 43 \\
\hline Bourgeois et al., 2007 & France & 6.1 & 3.64 & 7.97 & $8(100 \%)$ & 8 \\
\hline Caraballo et al., 2011 & Argentina & 8.5 & 4.25 & 9.5 & $33(73.33 \%)$ & 45 \\
\hline Cats et al., 2007 & Netherlands & 5.83 & 3.58 & 3.25 & $22(78.57 \%)$ & 28 \\
\hline Cook et al., 2004 & USA & NA & NA & 2 & $56(70.89 \%)$ & 79 \\
\hline Cukiert et al., 2009 & Brazil & 27 & 26.61 & 5.33 & $12(85.71 \%)$ & 14 \\
\hline Dagar et al., 2011 & India & 9.8 & 5.3 & 3.94 & $30(85.71 \%)$ & 35 \\
\hline Daniel et al., 2001 & India & 10.2 & 7.2 & 1.14 & $5(83.33 \%)$ & 6 \\
\hline Davies et al., 1993 & USA & 18 & NA & 28 & $10(58.82 \%)$ & 17 \\
\hline Delalande et al., 2007 & France & 7.89 & 5.76 & 4.54 & $60(74.07 \%)$ & 81 \\
\hline Devlin et al., 2003 & UK & 4.25 & NA & 3.4 & $17(51.52 \%)$ & 33 \\
\hline Dorfer et al., 2013 & Austria & 5.5 & 3.8 & 3.7 & $34(91.89 \%)$ & 37 \\
\hline Duchowny et al., 1998 & USA & 1.53 & 1.48 & 4.6 & $9(75 \%)$ & 12 \\
\hline Dunn et al., 1995 & UK & 8.57 & 7.76 & 1.86 & $4(57.14 \%)$ & 7 \\
\hline Greiner et al., 2011 & USA & 8.5 & 7.6 & 5.3 & $42(77.78 \%)$ & 54 \\
\hline Honavar et al., 1992 & UK & 12.5 & 5.7 & NA & $9(90 \%)$ & 10 \\
\hline Honda et al., 2013 & Japan & 0.36 & 0.35 & 6.57 & $8(66.67 \%)$ & 12 \\
\hline Kanev et al., 1997 & USA & NA & NA & 3.17 & $7(87.50 \%)$ & 8 \\
\hline Kawai et al., 2014 & Japan & 14.8 & 12.65 & 5.36 & $6(85.71 \%)$ & 7 \\
\hline Kestle et al., 2000 & USA & 4.49 & NA & 3 & $14(87.50 \%)$ & 16 \\
\hline Kim et al., 2008 & ROK & NA & NA & NA & $6(85.71 \%)$ & 7 \\
\hline Kishima et al., 2013 & Japan & 1.2 & NA & 6.93 & $4(66.67 \%)$ & 6 \\
\hline Korkman et al., 2005 & Finland & 10.75 & NA & 1 & $6(85.71 \%)$ & 7 \\
\hline Kossoff et al., 2003 & USA & 6.78 & 3.57 & 4.5 & $68(64.76 \%)$ & 105 \\
\hline Lee et al., 2014 & ROK & NA & NA & NA & $9(69.23 \%)$ & 13 \\
\hline Lettori et al., 2008 & Italy & 2.25 & 2.01 & 6.5 & $14(73.68 \%)$ & 19 \\
\hline Lew et al., 2014 & USA & 9.1 & 7.0 & 3.5 & 40 (83.33\%) & 48 \\
\hline Liang et al., 2013 & China & 21.96 & 17.72 & 3.15 & $22(88 \%)$ & 25 \\
\hline Limbrick et al., 2009 & USA & NA & NA & 28.6 & $38(77.55 \%)$ & 49 \\
\hline Lindsay et al., 1987 & UK & 11.88 & 10.01 & 12.56 & $14(82.35 \%)$ & 17 \\
\hline Marras et al., 2010 & Italy & 7.3 & 3.2 & 4.5 & $8(61.54 \%)$ & 13 \\
\hline Moosa et al., 2013 & USA & 7.02 & 5.15 & 5.3 & $112(65.88 \%)$ & 170 \\
\hline Ogunmekan et al., 1989 & Canada & 2.16 & 1.84 & NA & $5(50 \%)$ & 10 \\
\hline Otsuki et al., 2013 & Japan & NA & NA & NA & $12(66.67 \%)$ & 18 \\
\hline Ramantani et al., 2013 & Germany & 6.7 & 4.9 & 3.3 & $43(82.69 \%)$ & 52 \\
\hline Ramesha et al., 2009 & India & 10.44 & 4.23 & 2.78 & $6(66.67 \%)$ & 9 \\
\hline Scavarda et al., 2009 & Canada & 7 & 5.25 & 0.875 & $7(87.5 \%)$ & 8 \\
\hline Schramm et al., 201262 & Germany & 30 & 20.41 & 10.33 & $22(81.48 \%)$ & 27 \\
\hline Schramm et al., 201263 & Germany & 7.3 & 5.1 & 8.25 & $78(84.78 \%)$ & 92 \\
\hline Schropp et al., 2006 & Germany & 1.28 & 0.99 & 7.1 & $5(62.5 \%)$ & 8 \\
\hline Shimizu \& Maehara, 2000 & Japan & 6.9 & 5.5 & NA & $18(66.67 \%)$ & 27 \\
\hline Smith et al., 1991 & Canada & 13.5 & 9.4 & 5.8 & $18(75 \%)$ & 24 \\
\hline Sugimoto et al., 1999 & Canada & 1.31 & 0.9 & 3.08 & $8(72.72 \%)$ & 11 \\
\hline Tan et al., 2000 & China & 12 & 7 & 6.7 & $6(75 \%)$ & 8 \\
\hline Terra-Bustamante et al., 2007 & Brazil & 7.5 & 4.83 & 4.21 & $21(55.26 \%)$ & 38 \\
\hline Törmä et al., 1971 & Finland & 10.5 & NA & 5.67 & $2(33.33 \%)$ & 6 \\
\hline
\end{tabular}

(continued) 
TABLE 1. Studies included in the analyses (continued)

\begin{tabular}{|c|c|c|c|c|c|c|}
\hline Authors \& Year & Study Origin & $\begin{array}{l}\text { Patient Age at } \\
\text { Op (yrs) }\end{array}$ & $\begin{array}{c}\text { Duration of } \\
\text { Epilepsy (yrs)* }\end{array}$ & Follow-Up (yrs)* & $\begin{array}{c}\text { No. \& Rate of } \\
\text { Seizure Freedom }\end{array}$ & $\begin{array}{l}\text { Total No. of } \\
\text { Patients }\end{array}$ \\
\hline Torres et al., 2011 & Canada & 5.5 & 3.42 & 2.55 & $10(76.92 \%)$ & 13 \\
\hline Tubbs et al., 2005 & USA & 9.8 & 5.8 & 15.6 & $5(100 \%)$ & 5 \\
\hline Verity et al., 1982 & Canada & 7.5 & 6.12 & 10 & $6(85.71 \%)$ & 7 \\
\hline Villarejo-Ortega et al., 2013 & Spain & 5.9 & 4.63 & 3.1 & $10(58.82 \%)$ & 17 \\
\hline Villemure et al., 2006 & Switzerland & 8 & NA & 5 & $34(91.89 \%)$ & 37 \\
\hline Winston et al., 1992 & USA & 5.6 & 5.0 & 7.8 & $8(72.72 \%)$ & 11 \\
\hline Wyllie et al., 1997 & USA & NA & NA & NA & $11(68.75 \%)$ & 16 \\
\hline Yu et al., 2012 & China & NA & NA & NA & $17(89.47 \%)$ & 19 \\
\hline
\end{tabular}

NA = not available; ROK = Republic of Korea; UK = United Kingdom.

${ }^{*}$ Mean or median value.

TABLE 2. Associations between dichotomous variables of interest and seizure outcomes

\begin{tabular}{|c|c|c|c|c|c|c|}
\hline \multirow[b]{2}{*}{ Variable } & \multicolumn{2}{|c|}{ Outcome } & \multirow[b]{2}{*}{ OR $(95 \% \mathrm{Cl})$} & \multirow[b]{2}{*}{ p Value } & \multirow[b]{2}{*}{$\mathrm{P}^{2}$} & \multirow[b]{2}{*}{ Included Studies* } \\
\hline & Seizure Free & Seizure Recurrence & & & & \\
\hline \multicolumn{7}{|l|}{ Sex } \\
\hline Male & 239 & 94 & $1.15(0.79-1.67)$ & 0.46 & $0 \%$ & $\begin{array}{l}6 \text { stars on NOS: } 2,31,38,44,46,55,60,64,68 \\
\quad 71,72\end{array}$ \\
\hline Female & 170 & 72 & & & & $\begin{array}{l}7 \text { stars on NOS: } 8,18,20,22-24,32,39,48,51 \\
\quad 70,74,75\end{array}$ \\
\hline \multicolumn{7}{|l|}{ Etiology } \\
\hline Developmental & 239 & 121 & $0.61(0.46-0.82)$ & 0.001 & $0 \%$ & 6 stars on NOS: $21,35,38,44,46,62,68,72$ \\
\hline Nondevelopmental & 529 & 152 & & & & $\begin{array}{l}7 \text { stars on NOS: } 1,8,12,20,22-24,30,39,40,45 \\
\quad 49,51,54,63,70,75,76\end{array}$ \\
\hline \multicolumn{7}{|l|}{ Seizure semiology } \\
\hline Partial only & 160 & 57 & $1.84(1.18-2.89)$ & 0.008 & $0 \%$ & $\begin{array}{l}6 \text { stars on NOS: } 2,13,31,35,44,52,62,64,68 \\
\quad 71,72\end{array}$ \\
\hline Generalized & 119 & 67 & & & & 7 stars on NOS: $45,51,70,75$ \\
\hline \multicolumn{7}{|l|}{ Interictal EEG } \\
\hline Lateralized & 197 & 58 & $1.66(1.03-2.67)$ & 0.04 & $0 \%$ & 6 stars on NOS: 72 \\
\hline Nonlateralized & 111 & 47 & & & & 7 stars on NOS: $4,30,45,51,54$ \\
\hline \multicolumn{7}{|l|}{ Ictal EEG } \\
\hline Lateralized & 237 & 71 & $1.88(1.15-3.07)$ & 0.01 & $0 \%$ & 6 stars on NOS: 72 \\
\hline Nonlateralized & 67 & 39 & & & & 7 stars on NOS: $4,30,45,47,51,54$ \\
\hline \multicolumn{7}{|l|}{ Contralateral MRI } \\
\hline Abnormal & 50 & 36 & $0.46(0.27-0.77)$ & 0.004 & $10 \%$ & 6 stars on NOS: 64 \\
\hline Normal & 189 & 57 & & & & 7 stars on NOS: $4,45,51,54,75$ \\
\hline \multicolumn{7}{|l|}{ Surgical technique } \\
\hline Disconnective & 202 & 70 & $1.51(0.96-2.36)$ & 0.07 & $45 \%$ & 6 stars on NOS: $5,44,46$ \\
\hline Cortical removal & 102 & 51 & & & & 7 stars on NOS: $1,12,36,45,51,70$ \\
\hline \multicolumn{7}{|l|}{ Side of resection } \\
\hline Right & 188 & 56 & $1.17(0.79-1.73)$ & 0.43 & $0 \%$ & $\begin{array}{l}6 \text { stars on NOS: } 2,5,13,31,35,44,46,52,55,60 \text {, } \\
\quad 62,64,68,71,72\end{array}$ \\
\hline Left & 217 & 78 & & & & $\begin{array}{l}7 \text { stars on NOS: } 8,18,20,22-24,32,39,48,54 \\
\quad 67,70,74,75\end{array}$ \\
\hline
\end{tabular}

NOS = Newcastle-Ottawa Scale.

* Numbers to the right of the colon indicate reference numbers. 
A

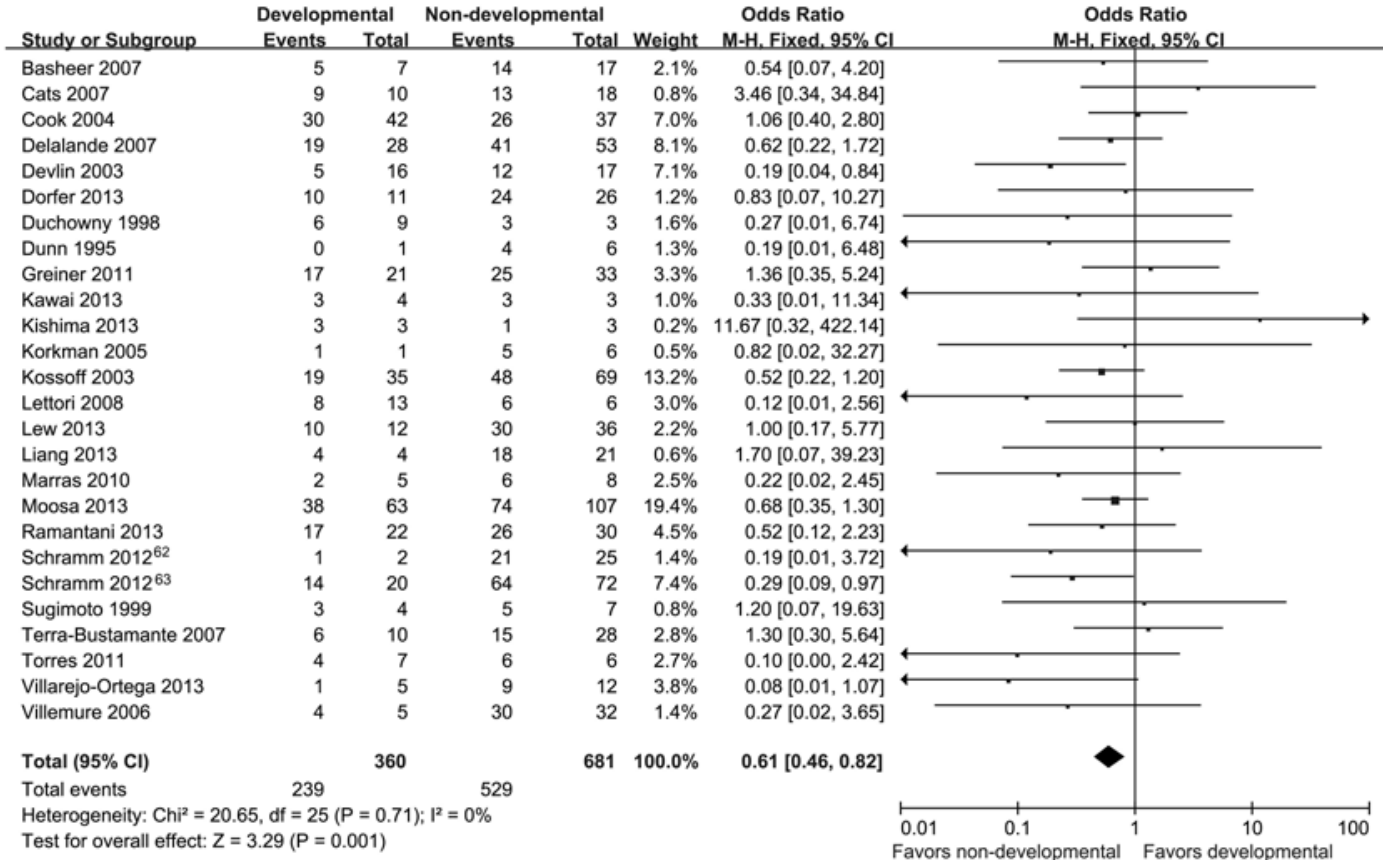

B

Partial only Generalized

Odds Ratio

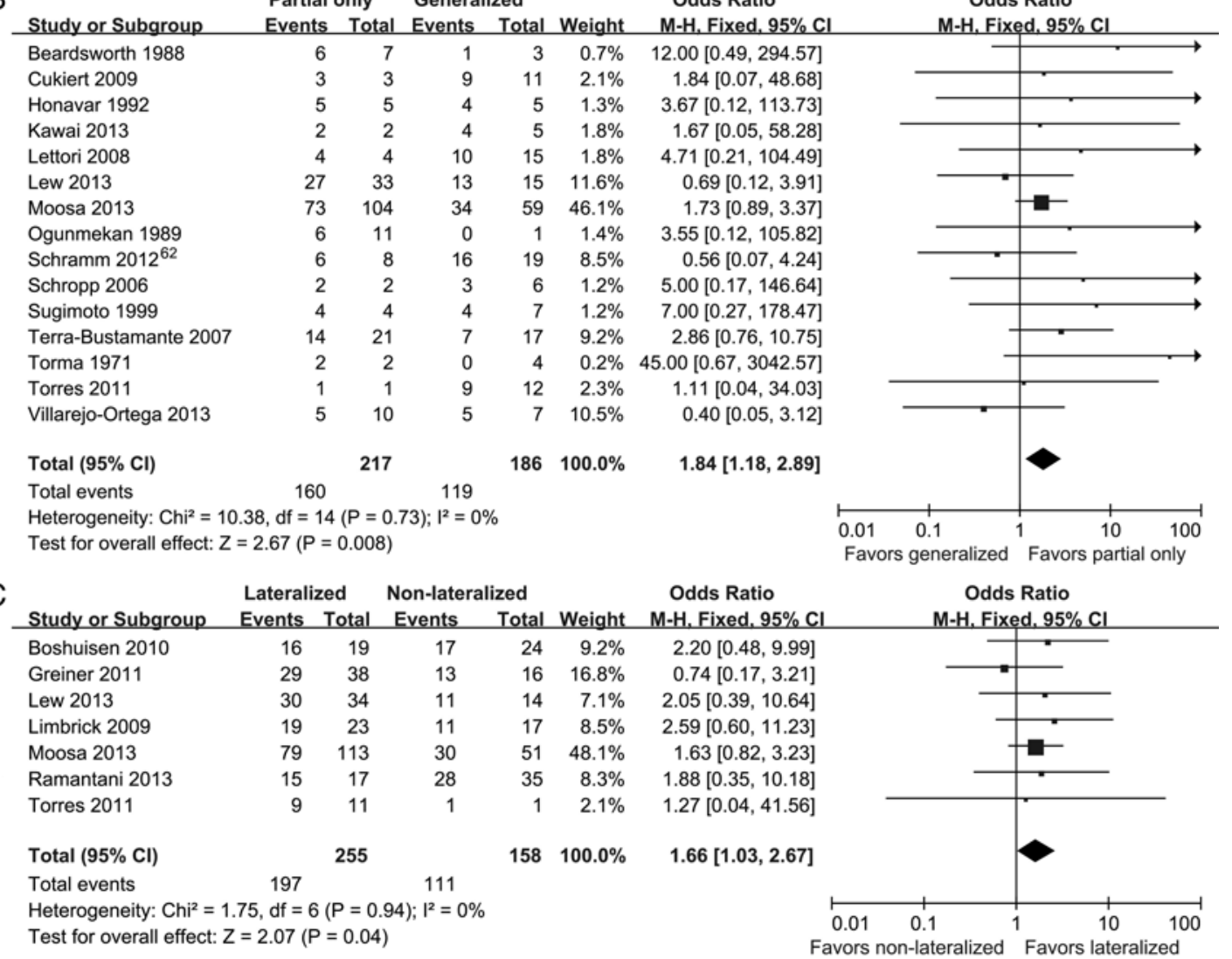

FIG. 2. Meta-analysis of seizure freedom with regard to epilepsy etiology (A, developmental vs nondevelopmental), seizure semiology (B, partial only vs generalized), interictal EEG findings (C, lateralized vs nonlateralized).

II, respectively, were MRI negative. ${ }^{43}$ The contralateral lesions from MRI-undetectable cortical dysplasia could be independently epileptogenic, and we postulate that they might account for the observed seizure recurrences after hemispheric surgery. Based on the above-mentioned evidence, comprehensive preoperative evaluation, including neuroimaging or neuroelectrophysiological examinations, should be performed on patients with suspected devel- 


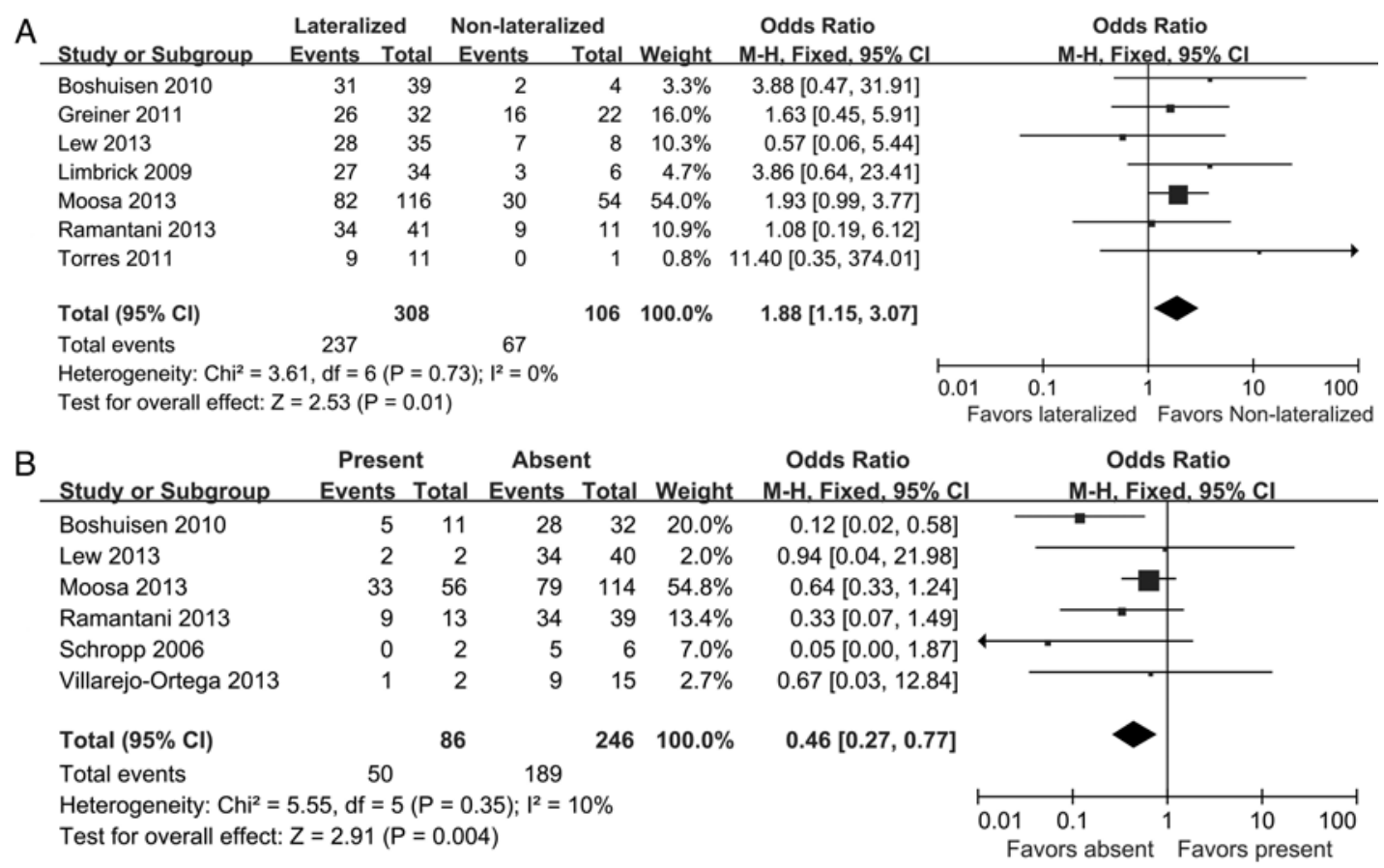

FIG. 3. Meta-analysis of seizure freedom with regard to ictal EEG findings (A, lateralized vs nonlateralized) and contralateral MRI abnormalities (B, present vs absent).

opmental disorders. Great efforts have been made to improve the detection of cortical dysplasia in patients with epilepsy. ${ }^{9,11,58,78}$ These novel techniques might be helpful for identifying bilateral cortical dysplasia in candidates for hemispheric surgery.

There are only 2 reports addressing the correlation between seizure semiology and seizure outcomes after hemispheric surgery, and no significant correlation was found because of the relatively small patient populations. ${ }^{45,51}$ In the present article, data extracted from 14 studies involving 391 patients indicate that patients with preoperative generalized or secondary generalized seizures were more likely to suffer from recurrent seizures than those without a history of generalized seizures. Similar to our findings, previous studies investigating epilepsy surgery for FCD, ${ }^{57}$ temporal lobe epilepsy, ${ }^{33}$ extratemporal lobe epilepsy, ${ }^{25}$ and tuberous sclerosis complex ${ }^{26}$ have suggested that generalized seizures appear to be a predictive factor for poor seizure control. We speculate that generalized seizures may be a manifestation of diffuse epileptogenic lesion(s), which may affect the contralateral hemisphere. Previous neuroelectrophysiological and neuroimaging studies suggest that generalized seizures are associated with multifocal irritative areas and more extended hypometabolism on fluorodeoxyglucose positron emission tomography (PET).3,59
Although scalp EEG is a routine preoperative examination for epilepsy surgery, there were conflicting opinions on the value of EEG in the evaluation of hemispheric surgery candidates. Some studies have suggested interictal or ictal bilateral EEG abnormalities did not predict poor outcomes following hemispherectomies. ${ }^{29,30}$ Moreover, Ciliberto et al. performed hemispherotomy on 7 patients with bilateral seizure onset, and they found that all patients improved in seizure control and overall quality of life. ${ }^{10} \mathrm{How}-$ ever, when taking seizure freedom into account, only 3 of the 7 patients were seizure-free after surgery, indicating that the seizure-free rate $(43 \%)$ in their series was much lower than the pooled rate $(73 \%)$ in our analysis. Carmant et al. suggested that preoperative EEG examinations were helpful in assessing the risk of seizure recurrence in patients undergoing an evaluation for hemispherectomy? Similar results were observed in our study; patients with lateralized interictal or ictal EEGs were more likely to be seizure-free after surgery as compared with those patients with bilateral abnormalities in EEGs.

Boshuisen et al. first reported that contralateral MRI abnormalities negatively affected postoperative seizure outcomes in patients who underwent hemispherectomy. ${ }^{4}$ Although other studies disagreed with their report, the majority of studies showed considerable, but not statistically significant, trends that the presence of contralateral

TABLE 3. Comparisons of continuous variables between seizure-free and seizure-recurrent groups

\begin{tabular}{lcccl}
\hline \multicolumn{1}{c}{ Variables } & WMD $(95 \% \mathrm{Cl})$ & $\mathrm{p}$ Value & $\left.\right|^{2}$ & Included Studies \\
\hline Age at seizure onset (yrs) & $0.43(0.07-0.79)$ & 0.02 & $66 \%$ & \multirow{2}{*}{ 6 stars on NOS: 2, 13, 44, 46, 52, 62, 64, 72 } \\
\cline { 1 - 3 } Age at op (yrs) & $1.15(0.07-2.23)$ & 0.04 & $63 \%$ & 7 stars on NOS: 0, 22-24, 48, 51, 54, 67, 70, 75 \\
\cline { 1 - 3 } Epilepsy duration (yrs) & $0.55(-0.32-1.41)$ & 0.22 & $50 \%$ & \\
\hline
\end{tabular}


MRI abnormalities were associated with seizure recurrence. $^{51,54,75}$ In the present study, we pooled the above-mentioned studies together and found statistical significance without substantial heterogeneity.

At least 3 limitations should be noted in the present meta-analysis. First, although the etiology of epilepsy, EEG, and MRI findings were identified as seizure outcome predictors in our study, we were not able to analyze the correlations among the 3 predictors in a meta-analysis. A study by Döring et al. demonstrated that bilateral EEG abnormalities were more common in hemispherectomy candidates with developmental etiology than in candidates with nondevelopmental etiology, both interictally and ictally. ${ }^{14}$ These studies raised the question of whether EEG or MRI findings could independently affect the postoperative seizure outcome. Moosa and colleagues identified lateralized ictal EEG onset as a positive predictor of seizure freedom in their univariate analysis, but the multivariate analysis confirmed that it was not an independent predictor. ${ }^{51} \mathrm{Sec}-$ ond, studies published in the non-English literature were not included in this analysis, which may lead to selection bias. Third, moderate-to-substantial heterogeneity was observed in some analyses, which was probably explained by the varieties of participants, preoperative evaluation, and surgical techniques in different epilepsy centers.

An important point we want to emphasize here is that although developmental disorders, generalized seizures, nonlateralization on EEG, and contralateral MRI abnormalities were identified as relative risk factors of seizure recurrence, each single factor should not be exclusively considered as an absolute contraindication to hemispheric surgery. The decision to perform hemispheric surgery must be made on the basis of the clinical evidence in its entirety, including epilepsy etiology, seizure semiology and severity of the epilepsy, EEG, MRI, cognitive conditions, and risk of neurological deficits after surgery.

\section{Conclusions}

In conclusion, hemispheric surgery for medically intractable epilepsy leads to favorable seizure outcomes, with a seizure-free rate of $73 \%$. Developmental disorders, generalized seizures, nonlateralization on EEG, and contralateral MRI abnormalities are relative risk factors of seizure recurrence after hemispheric surgery. However, given the limitations of the present study, more studies should be performed to examine our conclusions. In addition to the above-mentioned risk factors, other factors including the severity of the epilepsy, cognitive conditions, and the risk of new neurological deficits should be considered when making surgical decisions.

\section{Acknowledgments}

This work was supported by the Beijing Nova Program (Grant No. Z141107001814008) and the Beijing Municipal Administration of Hospitals Clinical Medicine Development (Grant No. ZY201305).

\section{References}

1. Basheer SN, Connolly MB, Lautzenhiser A, Sherman EM, Hendson G, Steinbok P: Hemispheric surgery in children with refractory epilepsy: seizure outcome, complications, and adaptive function. Epilepsia 48:133-140, 2007

2. Beardsworth ED, Adams CB: Modified hemispherectomy for epilepsy: early results in 10 cases. Br J Neurosurg 2:73-84, 1988

3. Blume WT: Clinical and electroencephalographic correlates of the multiple independent spike foci pattern in children. Ann Neurol 4:541-547, 1978

4. Boshuisen K, van Schooneveld MM, Leijten FS, de Kort GA, van Rijen PC, Gosselaar PH, et al: Contralateral MRI abnormalities affect seizure and cognitive outcome after hemispherectomy. Neurology 75:1623-1630, 2010

5. Bourgeois M, Crimmins DW, de Oliveira RS, Arzimanoglou A, Garnett M, Roujeau T, et al: Surgical treatment of epilepsy in Sturge-Weber syndrome in children. J Neurosurg 106 (1 Suppl):20-28, 2007

6. Caraballo R, Bartuluchi M, Cersósimo R, Soraru A, Pomata $\mathrm{H}$ : Hemispherectomy in pediatric patients with epilepsy: a study of 45 cases with special emphasis on epileptic syndromes. Childs Nerv Syst 27:2131-2136, 2011

7. Carmant L, Kramer U, Riviello JJ, Helmers SL, Mikati MA, Madsen JR, et al: EEG prior to hemispherectomy: correlation with outcome and pathology. Electroencephalogr Clin Neurophysiol 94:265-270, 1995

8. Cats EA, Kho KH, Van Nieuwenhuizen O, Van Veelen CW, Gosselaar PH, Van Rijen PC: Seizure freedom after functional hemispherectomy and a possible role for the insular cortex: the Dutch experience. J Neurosurg 107 (4 Suppl):275-280, 2007

9. Chassoux F, Rodrigo S, Semah F, Beuvon F, Landre E, Devaux B, et al: FDG-PET improves surgical outcome in negative MRI Taylor-type focal cortical dysplasias. Neurology 75:2168-2175, 2010

10. Ciliberto MA, Limbrick D, Powers A, Titus JB, Munro R, Smyth MD: Palliative hemispherotomy in children with bilateral seizure onset. J Neurosurg Pediatr 9:381-388, 2012

11. Colliot O, Bernasconi N, Khalili N, Antel SB, Naessens V, Bernasconi A: Individual voxel-based analysis of gray matter in focal cortical dysplasia. Neuroimage 29:162-171, 2006

12. Cook SW, Nguyen ST, Hu B, Yudovin S, Shields WD, Vinters $\mathrm{HV}$, et al: Cerebral hemispherectomy in pediatric patients with epilepsy: comparison of three techniques by pathological substrate in 115 patients. J Neurosurg 100 (2 Suppl Pediatrics):125-141, 2004

13. Cukiert A, Cukiert CM, Argentoni M, Baise-Zung C, Forster $\mathrm{CR}$, Mello VA, et al: Outcome after hemispherectomy in hemiplegic adult patients with refractory epilepsy associated with early middle cerebral artery infarcts. Epilepsia 50:1381-1384, 2009

14. Döring S, Cross H, Boyd S, Harkness W, Neville B: The significance of bilateral EEG abnormalities before and after hemispherectomy in children with unilateral major hemisphere lesions. Epilepsy Res 34:65-73, 1999

15. Dagar A, Chandra PS, Chaudhary K, Avnish C, Bal CS, Gaikwad S, et al: Epilepsy surgery in a pediatric population: a retrospective study of 129 children from a tertiary care hospital in a developing country along with assessment of quality of life. Pediatr Neurosurg 47:186-193, 2011

16. Dandy WE: Removal of right cerebral hemisphere for certain tumors with hemiplegia: Preliminary report. JAMA 90:823825,1928

17. Daniel RT, Joseph TP, Gnanamuthu C, Chandy MJ: Hemispherotomy for paediatric hemispheric epilepsy. Stereotact Funct Neurosurg 77:219-222, 2001

18. Davies KG, Maxwell RE, French LA: Hemispherectomy for intractable seizures: long-term results in 17 patients followed for up to 38 years. J Neurosurg 78:733-740, 1993

19. De Almeida AN, Marino R Jr, Aguiar PH, Jacobsen Teixeira M: Hemispherectomy: a schematic review of the current techniques. Neurosurg Rev 29:97-102, 2006 
20. Delalande O, Bulteau C, Dellatolas G, Fohlen M, Jalin C, Buret V, et al: Vertical parasagittal hemispherotomy: surgical procedures and clinical long-term outcomes in a population of 83 children. Neurosurgery 60:ONS19-ONS32, 2007

21. Devlin AM, Cross JH, Harkness W, Chong WK, Harding B, Vargha-Khadem F, et al: Clinical outcomes of hemispherectomy for epilepsy in childhood and adolescence. Brain 126:556-566, 2003

22. Dorfer C, Czech T, Dressler A, Gröppel G, Mühlebner-Fahrngruber A, Novak K, et al: Vertical perithalamic hemispherotomy: a single-center experience in 40 pediatric patients with epilepsy. Epilepsia 54:1905-1912, 2013

23. Duchowny M, Jayakar P, Resnick T, Harvey AS, Alvarez L, Dean P, et al: Epilepsy surgery in the first three years of life. Epilepsia 39:737-743, 1998

24. Dunn LT, Miles JB, May PL: Hemispherectomy for intractable seizures: a further modification and early experience. Br J Neurosurg 9:775-783, 1995

25. Englot DJ, Breshears JD, Sun PP, Chang EF, Auguste KI: Seizure outcomes after resective surgery for extra-temporal lobe epilepsy in pediatric patients. J Neurosurg Pediatr 12:126-133, 2013

26. Fallah A, Guyatt GH, Snead OC 3rd, Ebrahim S, Ibrahim GM, Mansouri A, et al: Predictors of seizure outcomes in children with tuberous sclerosis complex and intractable epilepsy undergoing resective epilepsy surgery: an individual participant data meta-analysis. PLoS One 8:e53565, 2013

27. Fauser S, Schulze-Bonhage A: Epileptogenicity of cortical dysplasia in temporal lobe dual pathology: an electrophysiological study with invasive recordings. Brain 129:82-95, 2006

28. Fogarasi A, Neuwirth M, Hegyi M, Siegler Z, Barsi P, Gyorsok Z, et al: Bilateral epilepsy surgery in a 4-year-old child. Neuropediatrics 35:360-363, 2004

29. González-Martínez JA, Gupta A, Kotagal P, Lachhwani D, Wyllie E, Lüders HO, et al: Hemispherectomy for catastrophic epilepsy in infants. Epilepsia 46:1518-1525, 2005

30. Greiner HM, Park YD, Holland K, Horn PS, Byars AW, Mangano FT, et al: Scalp EEG does not predict hemispherectomy outcome. Seizure 20:758-763, 2011

31. Honavar M, Janota I, Polkey CE: Rasmussen's encephalitis in surgery for epilepsy. Dev Med Child Neurol 34:3-14, 1992

32. Honda R, Kaido T, Sugai K, Takahashi A, Kaneko Y, Nakagwa E, et al: Long-term developmental outcome after early hemispherotomy for hemimegalencephaly in infants with epileptic encephalopathy. Epilepsy Behav 29:30-35, 2013

33. Janszky J, Janszky I, Schulz R, Hoppe M, Behne F, Pannek HW, et al: Temporal lobe epilepsy with hippocampal sclerosis: predictors for long-term surgical outcome. Brain 128:395-404, 2005

34. Kanev PM, Foley CM, Miles D: Ultrasound-tailored functional hemispherectomy for surgical control of seizures in children. J Neurosurg 86:762-767, 1997

35. Kawai K, Morino M, Iwasaki M: Modification of vertical hemispherotomy for refractory epilepsy. Brain Dev 36:124129,2014

36. Kestle J, Connolly M, Cochrane D: Pediatric peri-insular hemispherotomy. Pediatr Neurosurg 32:44-47, 2000

37. Kim SK, Wang KC, Hwang YS, Kim KJ, Chae JH, Kim IO, et al: Epilepsy surgery in children: outcomes and complications. J Neurosurg Pediatr 1:277-283, 2008

38. Kishima H, Oshino S, Tani N, Maruo Y, Morris S, Ming $\mathrm{Khoo} \mathrm{H}$, et al: Which is the most appropriate disconnection surgery for refractory epilepsy in childhood? Neurol Med Chir (Tokyo) 53:814-820, 2013

39. Korkman M, Granström ML, Kantola-Sorsa E, Gaily E, Paetau R, Liukkonen E, et al: Two-year follow-up of intelligence after pediatric epilepsy surgery. Pediatr Neurol 33:173-178, 2005
40. Kossoff EH, Vining EP, Pillas DJ, Pyzik PL, Avellino AM, Carson BS, et al: Hemispherectomy for intractable unihemispheric epilepsy etiology vs outcome. Neurology 61:887890,2003

41. Lee N, Radtke RA, Gray L, Burger PC, Montine TJ, DeLong GR, et al: Neuronal migration disorders: positron emission tomography correlations. Ann Neurol 35:290-297, 1994

42. Lee YJ, Lee JS, Kang HC, Kim DS, Shim KW, Eom S, et al: Outcomes of epilepsy surgery in childhood-onset epileptic encephalopathy. Brain Dev 36:496-504, 2014

43. Lerner JT, Salamon N, Hauptman JS, Velasco TR, Hemb M, Wu JY, et al: Assessment and surgical outcomes for mild type I and severe type II cortical dysplasia: a critical review and the UCLA experience. Epilepsia 50:1310-1335, 2009

44. Lettori D, Battaglia D, Sacco A, Veredice C, Chieffo D, Massimi L, et al: Early hemispherectomy in catastrophic epilepsy: a neuro-cognitive and epileptic long-term follow-up. Seizure 17:49-63, 2008

45. Lew SM, Koop JI, Mueller WM, Matthews AE, Mallonee JC: Fifty consecutive hemispherectomies: outcomes, evolution of technique, complications, and lessons learned. Neurosurgery 74:182-194, 2014

46. Liang S, Zhang G, Li Y, Ding C, Yu T, Wang X, et al: Hemispherectomy in adults patients with severe unilateral epilepsy and hemiplegia. Epilepsy Res 106:257-263, 2013

47. Limbrick DD, Narayan P, Powers AK, Ojemann JG, Park TS, Bertrand M, et al: Hemispherotomy: efficacy and analysis of seizure recurrence. J Neurosurg Pediatr 4:323-332, 2009

48. Lindsay J, Ounsted C, Richards P: Hemispherectomy for childhood epilepsy: a 36-year study. Dev Med Child Neurol 29:592-600, 1987

49. Marras CE, Granata T, Franzini A, Freri E, Villani F, Casazza M, et al: Hemispherotomy and functional hemispherectomy: indications and outcome. Epilepsy Res 89:104-112, 2010

50. McKenzie K: The present status of a patient who had the right cerebral hemisphere removed. JAMA 111:168-183, 1938

51. Moosa AN, Gupta A, Jehi L, Marashly A, Cosmo G, Lachhwani D, et al: Longitudinal seizure outcome and prognostic predictors after hemispherectomy in 170 children. Neurology 80:253-260, 2013

52. Ogunmekan AO, Hwang PA, Hoffman HJ: Sturge-WeberDimitri disease: role of hemispherectomy in prognosis. Can J Neurol Sci 16:78-80, 1989

53. Otsuki T, Honda R, Takahashi A, Kaido T, Kaneko Y, Nakai $\mathrm{T}$, et al: Surgical management of cortical dysplasia in infancy and early childhood. Brain Dev 35:802-809, 2013

54. Ramantani G, Kadish NE, Brandt A, Strobl K, Stathi A, Wiegand G, et al: Seizure control and developmental trajectories after hemispherotomy for refractory epilepsy in childhood and adolescence. Epilepsia 54:1046-1055, 2013

55. Ramesha KN, Rajesh B, Ashalatha R, Kesavadas C, Abraham M, Radhakrishnan VV, et al: Rasmussen's encephalitis: experience from a developing country based on a group of medically and surgically treated patients. Seizure 18:567-572, 2009

56. Rasmussen T: Hemispherectomy for seizures revisited. Can J Neurol Sci 10:71-78, 1983

57. Rowland NC, Englot DJ, Cage TA, Sughrue ME, Barbaro NM, Chang EF: A meta-analysis of predictors of seizure freedom in the surgical management of focal cortical dysplasia. J Neurosurg 116:1035-1041, 2012

58. Salamon N, Kung J, Shaw SJ, Koo J, Koh S, Wu JY, et al: FDG-PET/MRI coregistration improves detection of cortical dysplasia in patients with epilepsy. Neurology 71:1594-1601, 2008

59. Savic I, Altshuler L, Baxter L, Engel J Jr: Pattern of interictal hypometabolism in PET scans with fludeoxyglucose F 18 reflects prior seizure types in patients with mesial temporal lobe seizures. Arch Neurol 54:129-136, 1997 
60. Scavarda D, Major P, Lortie A, Mercier C, Carmant L: Periinsular hemispherotomy in children with stroke-induced refractory epilepsy. J Neurosurg Pediatr 3:115-120, 2009

61. Schramm J, Behrens E, Entzian W: Hemispherical deafferentation: an alternative to functional hemispherectomy. Neurosurgery 36:509-516, 1995

62. Schramm J, Delev D, Wagner J, Elger CE, von Lehe M: Seizure outcome, functional outcome, and quality of life after hemispherectomy in adults. Acta Neurochir (Wien) 154:1603-1612, 2012

63. Schramm J, Kuczaty S, Sassen R, Elger CE, von Lehe M: Pediatric functional hemispherectomy: outcome in 92 patients. Acta Neurochir (Wien) 154:2017-2028, 2012

64. Schropp C, Sörensen N, Krauss J: Early periinsular hemispherotomy in children with Sturge-Weber syndrome and intractable epilepsy-outcome in eight patients. Neuropediatrics 37:26-31, 2006

65. Shimizu H, Maehara T: Modification of peri-insular hemispherotomy and surgical results. Neurosurgery 47:367-373, 2000

66. Simone IL, Federico F, Tortorella C, De Blasi R, Bellomo R, Lucivero V, et al: Metabolic changes in neuronal migration disorders: evaluation by combined MRI and proton MR spectroscopy. Epilepsia 40:872-879, 1999

67. Smith SJ, Andermann F, Villemure JG, Rasmussen TB, Quesney LF: Functional hemispherectomy: EEG findings, spiking from isolated brain postoperatively, and prediction of outcome. Neurology 41:1790-1794, 1991

68. Sugimoto T, Otsubo H, Hwang PA, Hoffman HJ, Jay V, Snead OC III: Outcome of epilepsy surgery in the first three years of life. Epilepsia 40:560-565, 1999

69. Tan Q, Sun K, Pan Y, Sun K, Hua C, Qiao L: Long-term results of functional hemispherectomy for intractable seizures. Stereotact Funct Neurosurg 75:90-95, 2000

70. Terra-Bustamante VC, Inuzuka LM, Fernandes RM, EscorsiRosset S, Wichert-Ana L, Alexandre V Jr, et al: Outcome of hemispheric surgeries for refractory epilepsy in pediatric patients. Childs Nerv Syst 23:321-326, 2007

71. Törmä T, Donner M: Hemispherectomy in early hemiplegia and intractable epilepsy. Acta Paediatr Scand 60:545-552, 1971

72. Torres CV, Fallah A, Ibrahim GM, Cheshier S, Otsubo H, Ochi A, et al: The role of magnetoencephalography in children undergoing hemispherectomy. J Neurosurg Pediatr 8:575-583, 2011

73. Tubbs RS, Nimjee SM, Oakes WJ: Long-term follow-up in children with functional hemispherectomy for Rasmussen's encephalitis. Childs Nerv Syst 21:461-465, 2005

74. Verity CM, Strauss EH, Moyes PD, Wada JA, Dunn HG,
Lapointe JS: Long-term follow-up after cerebral hemispherectomy: neurophysiologic, radiologic, and psychological findings. Neurology 32:629-639, 1982

75. Villarejo-Ortega F, García-Fernández M, Fournier-Del Castillo C, Fabregate-Fuente M, Álvarez-Linera J, De PradaVicente I, et al: Seizure and developmental outcomes after hemispherectomy in children and adolescents with intractable epilepsy. Childs Nerv Syst 29:475-488, 2013

76. Villemure JG, Daniel RT: Peri-insular hemispherotomy in paediatric epilepsy. Childs Nerv Syst 22:967-981, 2006

77. Villemure JG, Mascott CR: Peri-insular hemispherotomy: surgical principles and anatomy. Neurosurgery 37:975-981, 1995

78. Wagner J, Weber B, Urbach H, Elger CE, Huppertz HJ: Morphometric MRI analysis improves detection of focal cortical dysplasia type II. Brain 134:2844-2854, 2011

79. Winston KR, Welch K, Adler JR, Erba G: Cerebral hemicorticectomy for epilepsy. J Neurosurg 77:889-895, 1992

80. Wyllie E, Comair YG, Kotagal P, Bulacio J, Bingaman W, Ruggieri P: Seizure outcome after epilepsy surgery in children and adolescents. Ann Neurol 44:740-748, 1998

81. Yu T, Zhang G, Kohrman MH, Wang Y, Cai L, Shu W, et al: A retrospective study comparing preoperative evaluations and postoperative outcomes in paediatric and adult patients undergoing surgical resection for refractory epilepsy. Seizure 21:444-449, 2012

82. Zamponi N, Rychlicki F, Cardinali C, Luchetti A, Trignani $\mathrm{R}$, Ducati A: Intermittent vagal nerve stimulation in paediatric patients: 1-year follow-up. Childs Nerv Syst 18:61-66, 2002

\section{Disclosure}

The authors report no conflict of interest concerning the materials or methods used in this paper or the findings specified in this paper.

\section{Author Contributions}

Conception and design: JG Zhang. Acquisition of data: $\mathrm{Hu}, \mathrm{C}$ Zhang. Analysis and interpretation of data: $\mathrm{Hu}, \mathrm{C}$ Zhang, $\mathrm{K}$ Zhang. Drafting the article: Hu. Critically revising the article: all authors. Reviewed submitted version of manuscript: all authors. Approved the final version of the manuscript on behalf of all authors: JG Zhang. Statistical analysis: Hu, C Zhang.

\section{Correspondence}

Jian-guo Zhang, Beijing Neurosurgical Institute, Tiantan Xili 6, Dongcheng, Beijing 100050, China. email: zjguo73@126.com. 